\title{
Adequate Decongestion Is Still the Question in Heart Failure
}

\author{
Nosheen Reza ${ }^{a}$ Shelley Zieroth ${ }^{b}$ \\ aDivision of Cardiovascular Medicine, Department of Medicine, Perelman School of Medicine at \\ the University of Pennsylvania, Philadelphia, PA, USA; ${ }^{b}$ Section of Cardiology, Max Rady College of \\ Medicine, University of Manitoba, Winnipeg, MB, Canada
}

\section{Keywords \\ Heart failure - Congestion - Lung impedance - Biomarkers . Outcomes}

One of the greatest challenges in the contemporary management of acute heart failure (HF) is the quantification of predischarge pulmonary congestion. Failure to resolve symptoms of congestion at hospital discharge is associated with increased risks for rehospitalization for HF and all-cause mortality [1]. Using clinical assessment to categorize patients by congestion and perfusion status can be used to predict clinical outcomes in patients with HF [2]. However, some traditional history and physical examination findings used to assess pulmonary congestion status, like edema, rales, and wheezing, lack sensitivity for the diagnosis of decompensated HF [3]. Similarly, chest radiography findings like pulmonary venous congestion, interstitial edema, and pleural effusions may not reliably identify and categorize patients with volume overload [3]. In addition, patients with HF can have hemodynamic congestion despite clear lung fields on chest imaging [4]. To augment the diagnostic accuracy of the assessment of congestion in patients with acute and chronic HF, additional data from circulating biomarkers

karger@karger.com www.karger.com/crd

(c) 2020 S. Karger AG, Basel

Karger' like natriuretic peptides [5], imaging technologies such as lung ultrasonography [6], and implantable monitors such as pulmonary artery pressure sensors [7] are being increasingly incorporated into the longitudinal care of patients with diverse subtypes of HF. Despite the proliferation of these strategies, durable reductions in HF rehospitalizations and HF-related mortality have yet to be realized. There remains a substantial need to identify a cost-effective, widely applicable, easily implemented, and accurate strategy to identify and treat patients with hemodynamic and clinical congestion due to HF.

In this issue of Cardiology, Kleiner Shochat et al. [8] attempt to address this need using the measurement of noninvasive lung impedance (LI), a strategy they introduced in the IMPEDANCE-HF trial [9]. In the parent trial, the investigators used a novel high-sensitivity monitor based on an algorithm that derived net LI by subtracting the calculated chest wall impedance from the total transthoracic impedance. With this derivation method, net LI would theoretically be most representative of pulmonary congestion. The authors evaluated 256 patients with chronic New York Heart Association Class II-IV HF and left ventricular ejection fraction $\leq 35 \%$ who were admitted for acute HF within a year before recruitment and 
randomized them to a control group treated by clinical assessment-guided conventional therapy or an intervention group whose treatment strategy included guidance by noninvasive LI monitoring. Significantly, fewer patients in the intervention group experienced the primary efficacy endpoint of acute HF hospitalization, and fewer patients suffered all-cause and HF-related mortality. The IMPEDANCE-HF trial was extended to assess the association between change in pulmonary fluid content measured by LI during a HF hospitalization and hospital readmissions. Unfortunately, difficulties with data acquisition and inability to attribute the change in pulmonary congestion solely to active decongestion rendered this finding nonviable as a suitable risk predictor [10].

In the current post hoc analysis of the IMPEDANCEHF extended trial, the authors sought to demonstrate [1] that LI-guided assessment of predischarge pulmonary congestion predicts time to hospital readmission (TTR) and time to death (TTD) and [2] that $\Delta \mathrm{LIR}_{\text {discharge, a cal- }}$ culated parameter that represents the degree of lung congestion at discharge compared to the normal lung fluid state, outperforms other clinical parameters in the prediction of TTR and TTD. An extensive 26 variables spanning demographics, physical exam findings, and laboratory, and medication data were considered as potential predictors for TTR and TTD; the rationale for their selection was not provided.

Quite notable was the high rates of events among the 290 participants in this study. Over the $57.2 \pm 39$ months of follow-up, 206 patients (71\%) of patients were admitted 766 times due to decompensated HF, roughly 4 admissions per patient, and 155 patients (53\%) died, reinforcing the high morbidity and mortality burden for patient with chronic $\mathrm{HF}$ with reduced ejection fraction. The overall follow-up duration for the control group was significantly shorter compared with the LI-guided group. In their multivariate analysis of TTR, $\Delta \mathrm{LIR}_{\text {discharge }}$ was the dominant independent predictor of TTR, compared with their other 5 independent predictors, and $\Delta \mathrm{LIR}_{\text {admission }}$ was the second most significant predictor. Interestingly, the difference between the 2 measurements, a calculation representing the improvement in pulmonary congestion during the hospital admission, did not independently predict TTR. Similarly, in the TTD analysis, $\Delta \mathrm{LIR}_{\text {discharge }}$ was the most powerful predictor. In a head-to-head comparison by quartile, $\Delta \mathrm{LIR}_{\text {discharge }}$ was more accurate in predicting hospitalizations and deaths at 30 days and 1 -year compared with log-transformed NTproBNP discharge. Categorization into NTproBNP quartiles seemed to be based on the range of patient values and not on previ- ously established thresholds. Providing the baseline range of patients' NTproBNP values may have provided an interesting opportunity to compare with previous prognostic studies $[11,12]$.

Overall, the authors provide provocative data in support of pursuing thoracic and LI monitoring and LI-guided therapy to refine assessments and outcomes of pulmonary congestion. These were the results of a post hoc analysis of the IMPEDANCE-HF extended trial, a singleblinded, two-center trial, and therefore, these results should be considered as exploratory for hypothesis generation. The authors state that the benefits of their technique include cost-effectiveness, ease of use, and good intra- and inter-rater reliability but also acknowledge the potential bias in the decision of readmission in the LIguided group. Further studies in larger and more generalizable populations should be performed with measures to minimize bias to further demonstrate these potential benefits of the technology. Baseline medical therapy in the IMPEDANCE-HF trial did not include angiotensin receptor-neprilysin inhibitors, now an important pillar of guideline-directed medical therapy for HF with reduced ejection fraction and one proven to reduce HF hospitalizations and mortality. Studying the additive benefit of LI-guided therapy on top of modern-guideline directed medical therapy will be important. A significant majority of the study population were men with ischemic cardiomyopathy; diversification of future trial participants is critical to evaluate potential sex-dependent and HF etiological effects on impedance measurements. Finally, and perhaps most importantly, this study demonstrates the vast numbers of patients with HF who do not achieve adequate decongestion at hospital discharge, even in intervention-guided trials, and highlights the urgency to better identify and treat patients with hemodynamic and clinical congestion due to HF.

\section{Conflict of Interest Statement}

The authors have no conflicts of interest to disclose.

\section{Funding Sources}

N.R. is supported by the National Center for Advancing Translational Sciences of the National Institutes of Health under award number KL2TR001879. The content is solely the responsibility of the authors and does not necessarily represent the official views of the National Institutes of Health. 


\section{References}

1 Ambrosy AP, Pang PS, Khan S, Konstam MA, Fonarow GC, Traver B, et al. Clinical course and predictive value of congestion during hospitalization in patients admitted for worsening signs and symptoms of heart failure with reduced ejection fraction: findings from the EVEREST trial. Eur Heart J. 2013 Mar; 34(11):835-43.

2 Nohria A, Tsang SW, Fang JC, Lewis EF, Jarcho JA, Mudge GH, et al. Clinical assessment identifies hemodynamic profiles that predict outcomes in patients admitted with heart failure. J Am Coll Cardiol. 2003 May 21;41(10): 1797-804.

3 Wang CS, FitzGerald JM, Schulzer M, Mak E, Ayas NT. Does this dyspneic patient in the emergency department have congestive heart failure? JAMA. 2005 Oct 19;294(15):1944-56.

4 Thibodeau JT, Drazner MH. The role of the clinical examination in patients with heart failure. JACC Heart Fail. 2018;6(7):543-51.
5 Felker GM, Anstrom KJ, Adams KF, Ezekowitz JA, Fiuzat M, Houston-Miller N, et al. Effect of natriuretic peptide-guided therapy on hospitalization or cardiovascular mortality in high-risk patients with heart failure and reduced ejection fraction: a randomized clinical trial. JAMA. 2017 22;318(8):713-20.

6 Platz E, Campbell RT, Claggett B, Lewis EF, Groarke JD, Docherty KF, et al. Lung ultrasound in acute heart failure: prevalence of pulmonary congestion and short- and longterm outcomes. JACC Heart Fail. 2019;7(10): 849-58.

7 Abraham WT, Adamson PB, Bourge RC, Aaron MF, Costanzo MR, Stevenson LW, et al. Wireless pulmonary artery haemodynamic monitoring in chronic heart failure: a randomised controlled trial. Lancet. 2011 Feb 19; 377(9766):658-66.

8 Kleiner Shochat M, Kapustin D, Fudim M, Ambrosy AP, Glantz J, Kazatsker M, et al. The degree of the pre-discharge pulmonary congestion in patients hospitalized for worsening heart failure predicts readmissions and mortality. Cardiology. 2020.
9 Shochat MK, Shotan A, Blondheim DS, Kazatsker M, Dahan I, Asif A, et al. Non-invasive lung IMPEDANCE-guided preemptive treatment in chronic heart failure patients: a randomized controlled trial (IMPEDANCE-HF Trial). J Card Fail. 2016 Sep;22(9):713-22.

10 Kleiner Shochat M, Fudim M, Shotan A, Blondheim DS, Kazatsker M, Dahan I, et al. Prediction of readmissions and mortality in patients with heart failure: lessons from the IMPEDANCE-HF extended trial. ESC Heart Fail. 2018;5(5):788-99.

11 Goetze JP, Bruneau BG, Ramos HR, Ogawa T, de Bold MK, de Bold AJ. Cardiac natriuretic peptides. Nat Rev Cardiol. 2020 May 22.

12 Zile MR, Claggett BL, Prescott MF, McMurray JJ, Packer M, Rouleau JL, et al. Prognostic implications of changes in N-terminal Pro-Btype natriuretic peptide in patients with heart failure. J Am Coll Cardiol. 2016 Dec 6;68(22): 2425-36. 